\title{
PLANNING INFORMATION SYSTEM STRATEGY PT. DIAN HARDESA JAKARTA
}

\author{
Muhamad Awiet Wiedanto Prasetyo \\ Program Studi Sistem Informasi \\ STMIK AMIKOM Purwokerto \\ Email: mawp@amikompurwokerto.ac.id \\ Kiki Eliyanti \\ Program Studi Sistem Informasi \\ STMIK AMIKOM Purwokerto \\ Email: eliyanti683@gmail.com
}

\begin{abstract}
ABSTRAK
PT. Dian Hardesa merupakan sebuah perusahaan yang bergerak Bidang Kontraktor Jasa Konstruksi yang berfokus pada Pelayanan Mekanikal, Elektrikal dan Elektronik. Infrastruktur jaringan intranet yang terhubung dengan beberapa personal computer, notebook, printer, mesin fotocopy dan aplikasi Microsoft Office untuk menjalankan proses bisnis perusahaan. Dengan infrastuktur teknologi dan sistem yang ada, terdapat kendala perusahaan seperti divisi stock barang yang terjadi kelebihan material, pengawasan sumber daya manusia yang mengakibatkan karyawan melakukan manipulasi data presensi dan penyajian laporan keuangan yang mengakibatkan tidak akuratnya data pada perusahaan. Dengan menggunakan Metode Ward and Peppard dan tools SWOT Analysis, Value Chain Analysis, McFarlan Strategic Grid Analysis, Five Force Model Porter Analysis, Critical Success Factor Analysis. Perencanaan Information System Strategy pada PT. Dian Hardesa menghasilkan rekomendasi portofolio sistem informasi keuangan, sistem informasi karyawan, sistem informasi absensi, sistem informasi ketersediaan barang, sistem informasi pelanggan, sistem informasi supplier, sistem informasi mitra kerja, sistem informasi manajemen aset, website perusahaan, sosial media perusahaan, knowledge management system, contructor planning application, sistem penunjang keputusan tender dan keputusan rekruitmen karyawan.
\end{abstract}

Kata kunci: is strategy; ward and peppard.

\section{ABSTRACT}

PT. Dian Hardesa company engaged in the field of Construction Services Contractors focusing on Mechanical, Electrical and Electronic Services. Intranet network infrastructure that is connected to several personal computers, notebooks, printers, photocopying machines and utilizes Microsoft Office applications to run company business processes. With the existing technology infrastructure and systems, there are corporate constraints such as stock goods division that occurs in excess material, supervision of Human Resources which results in employees manipulating data on the presence and presentation of financial statements resulting in inaccurate data on the company. Using the Ward and Peppard Method and tools SWOT Analysis, Value Chain Analysis, McFarlan Strategic Grid Analysis, Porter's Five Force Model Analysis, Critical Success Factors Analysis. Planning Information System Strategy at PT. Dian Hardesa produced a recommendation for a financial information system portfolio, employee information system, attendance information system, goods availability information system, customer information system, supplier information system, work partner information system, asset management information system, company website, corporate social media, knowledge management system, contructor planning application, tender decision support system and employee recruitment.

Keywords: is strategy; ward and peppard.

\section{PENDAHULUAN}

PT. Dian Hardesa merupakan sebuah perusahaan yang bergerak dibidang Kontraktor Jasa Konstruksi yang berfokus pada Pelayanan Mekanikal, Elektrikal dan Elektronik yang berdiri Pada Tanggal 16 Mei 1983. Berdasarkan Lembaga Pengembangan Jasa Konruksi Nasional, perusahaan yang bergerak pada Jasa Kontruksi mencapai 182.800 perusahaan dan meningkat sebanyak 5\% setiap tahunnya yang mengakibatkan persaingan semakin meningkat. Perusahaan seperti PT. Adhi Karya Persero tbk, Dinas Kesehatan dan Dinas Pendidikan, salah satu perusahaan atau instansi yang pernah menjalin kerjasama dengan PT. Dian Hardesa. 
Perkembangan segi teknologi informasi mengharuskan semua individu atau sebuah organisasi harus mengikuti untuk mencapai tujuan bisnis yang lebih efisien dan efektif. Sebagai contohnya dapat membantu perusahaan untuk mengetahui kinerja dari setiap karyawan atau lebih mudah mempromosikan sebuah produk yang dihasilkan untuk dipasarkan ke masyarakat luas. Dengan PT. Dian Hardesa menggunakan infrastruktur jaringan intranet yang terhubung dengan beberapa personal komputer, notebook, printer, mesin fotocopy dan aplikasi Microsoft Office. Dengan infrastuktur teknologi dan sistem yang ada, terdapat kendala perusahaan seperti divisi stock barang yang terjadi kelebihan material, pengawasan Sumber Daya Manusia (SDM) yang mengakibatkan karyawan melakukan manipulasi data presensi dan penyajian laporan keuangan yang mengakibatkan tidak akuratnya data pada perusahaan.

Information Technology/Information System (IT/IS) dimanfaatkan agar dapat meningkatkan daya saing perusahaan dan sebagai salah satu alat untuk mencapai keunggulan yang kompetitif serta melakukan perencanaan IT/IS untuk mengetahui kebutuhan perusahaan tujuan perusahaan [7]. Adanya dukungan dari stakeholder pemanfaatan IT/IS yang memberikan margin bagi organisasi tentunya melibatkan pengembangan hierarki yang terintegritas, saling kordinasi proses kegiatan bisninya dan menentukan sasaran organisasi untuk mencapat sebuah tujuan [2].

Sistem yang digunakan organisasi untuk menyimpan sekumpulan informasi, mengolah, mengubah, menghapus dan menambah informasi. Hasil rekayasa manusia terhadap proses memberikan informasi dan ke penerima sehingga hal ini dapat mempercepat penyampaian informasi dan dengan mudah memperluas sebarannya [6]. Perencanaan Strategis Sistem Informasi (PSSI) merupakan pencapaian yang dapat dihasilkan dalam jangka panjang atau jangka pendek yang menggambarkan tujuan sistem berserta arsitektur teknologi untuk kepentingan organisasi [8]. Penggabungan dari user, hardware, software, communication network, sumber daya berupa informasi data dan kebijakan untuk menentukan siapa yang menyimpan, mendapatkan kembali sebuah informasi, mengubah dan menyebarkan informasi organisasi [4]. Perencanaan strategi sistem informasi merupakan strategi jangka panjang tentang penerapan atau pengimplementasian yang sesuai dengan kebutuhan perusahaaan, strategi ini bertujuan untuk mewujudkan tujuan perusahaan.

\section{METODOLOGI PENELITIAN}

\subsection{Analisis Lingkungan Bisnis}

\subsubsection{Strength Weakness Opportunities Threats Analysis}

Bisa disebut dengan Analisis SWOT mencakup Strength Analysis digunakan untuk mengidentifikasi kekuatan dan kemampuan sumber daya dari perusahaan untuk meningkatkan daya saing antar perusahaan bergerak bidang yang sama. Weakness Analysis digunakan untuk mengidentifikasi kecacatan sumber dayanya yang menjadi kelemahan sehingga tidak menguntungkan babgi perusahaan. Opportunities Analysis digunakan untuk mengidentifikasi peluang yang kemungkinan terjadi pada pasar, sehingga bagi perusahaan hal ini menjadi kesempatan meminimalisir kelemahan menjadikan kekuatan perusahaan. Threats Analysis digunakan untuk mengidentifikasi ancaman yang akan terjadi dalam waktu mendatang, sehingga dapat meminimalisir kelemahan perusahaan.

\subsubsection{Critical Success Factor Analysis}

Bisa disebut dengan Analisa CSF merupakan suatu ketentuan perusahaan dengan memperhatikan lingkungan sekitar dapat berpengaruh pada keberhasilan atau kegagalan perusahaan. Sehingga tujuannya menginterpretasikan secara lebih jelas aktivitas yang harus dilakukan dan informasi apa yang dibutuhkan [1].

\subsubsection{Value Chain Analysis}

Value Chain Analysis digunakan untuk memetakan proses kerja organisasi menjadi dua kategori aktivitas yaitu aktivitas utama dan aktivitas pendukung. Mengacu pada dokumen organisasi yang menyebutkan tugas dan fungsi setiap unit kerja berdasarkan pengamatan yang dilakukan terhadap proses kerja yang terjadi di masing-masing unit kerja [5].

\subsubsection{Five Force Models Analysis}

Five Force Models Analysis digunakan untuk mengevaluasi struktur lingkungan bisnis dan tantangan dari pesaing suatu perusahaan. Hasil diagram kompetitif model digunakan sebagai dasar identifikasi 
peluang dari eksternal organisasi dalam pemanfaatan IT/IS yang dapat meningkatkan keunggulan kompetitif bisnisnya [3].

\subsubsection{McFarlan Strategic Grid Analysis}

McFarlan Strategic Grid Analysis digunakan untuk memetakan IT/IS berdasarkan kontribusi suatu perusahaan. Pemetaan dilakukan pada kuadran strategic, kuadran high potential, kuadran key operation dan kuadran support. Dari hasil pemetaan, dapat merupakan konstribusi sebuah aplikasi yang digunakan dalam jangka panjang suatu perusahaan.

\subsection{Analisis Strategi Sistem Informasi}

Proses perumusan strategi sistem informasi merupakan tahapan menentukan sistem informasi berdasarkan hasil analisis yang telah dilakukan sebelumnya. Pembuatan perencanaan strategi sistem informasi dan penyusunan aplikasi dimana yang akan datang mengacu kepada hasil dari analisis. Proses perumusan strategi sistem informasi nantinya akan menghasilkan strategi sistem informasi. Setelah itu, membuat portofolio aplikasi.

\section{HASIL PENELITIAN DAN PEMBAHASAN}

\subsection{Kondisi IT/IS Perusahaan}

Analisis ini mencakup seluruh sumber daya SI/TI yang saat ini ada dan dimanfaatkan pada PT. Dian Hardesa dalam proses bisnis. Adapun sumber daya SI/TI yang ada di PT. Dian Hardesa adalah sebagai berikut:

\subsubsection{Software}

Saat ini, PT. Dian Hardesa dalam menjalankan kegiatan bisnis masih dilakukan dengan menggunakan perangkat lunak Windows 2010, software Microsoft office 2010, seperti Microsoft Office Word, Microsoft Office Ecxel dan Microsoft Office Power Point.

Tabel 1. Software yang digunakan setiap divisi perusahaan

\begin{tabular}{|c|c|c|c|}
\hline Direksi & Ms. Word & Ms. Excel & Ms. Power Point \\
\hline $\begin{array}{l}\text { Direktur } \\
\text { Utama }\end{array}$ & $\begin{array}{l}\text { Laporan tahunan } \\
\text { perusahaan yang akan } \\
\text { diserahkan ke Komisaris. }\end{array}$ & $\begin{array}{l}\text { Laporan tahunan } \\
\text { perusahaan yang akan } \\
\text { diserahkan ke } \\
\text { Komisaris. }\end{array}$ & \\
\hline $\begin{array}{l}\text { Direktur } \\
\text { Oeprasional }\end{array}$ & $\begin{array}{l}\text { Laporan kegiatan } \\
\text { operasional anggaran } \\
\text { kegiatan, } \\
\text { sumber daya perusahaan. }\end{array}$ & $\begin{array}{l}\text { Laporan kegiatan } \\
\text { operasional } \\
\text { perusahaan, } \\
\text { sumber daya } \\
\text { perusahaan. }\end{array}$ & $\begin{array}{l}\text { Presentasi seperti, } \\
\text { ingin mengadakan } \\
\text { kegiatan ataupun } \\
\text { setelah selesai } \\
\text { kegiatan. }\end{array}$ \\
\hline $\begin{array}{l}\text { Direktur } \\
\text { Teknik }\end{array}$ & $\begin{array}{l}\text { Membuat laporan } \\
\text { perkembangan proyek } \\
\text { dan laporan akhir } \\
\text { proyek. }\end{array}$ & $\begin{array}{l}\text { Membuat laporan } \\
\text { proyek dan laporan } \\
\text { akhir proyek. }\end{array}$ & $\begin{array}{l}\text { Presentasi tentang } \\
\text { proyek. }\end{array}$ \\
\hline $\begin{array}{l}\text { Direktur } \\
\text { Keuangan }\end{array}$ & $\begin{array}{l}\text { Laporan keuangan } \\
\text { perusahaan (harian } \\
\text { hingga tahunan). }\end{array}$ & $\begin{array}{l}\text { Laporan keuangan } \\
\text { perusahaan (harian } \\
\text { hingga tahunan). }\end{array}$ & $\begin{array}{l}\text { Untuk bahan } \\
\text { presentasi tentang } \\
\text { keuangan } \\
\text { perusahaan. }\end{array}$ \\
\hline $\begin{array}{l}\text { Manajer } \\
\text { Operasional }\end{array}$ & $\begin{array}{l}\text { Laporan perkembangan } \\
\text { proyek, laporan alat } \\
\text { kontraktor serta sarana } \\
\text { prasarana proyek. }\end{array}$ & $\begin{array}{l}\text { Laporan } \\
\text { perkembangan proyek, } \\
\text { laporan alat kontraktor } \\
\text { serta sarana prasarana } \\
\text { proyek. }\end{array}$ & $\begin{array}{l}\text { Untuk bahan } \\
\text { presentasi tentang } \\
\text { tender proyek. }\end{array}$ \\
\hline $\begin{array}{l}\text { Manajer } \\
\text { Proyek }\end{array}$ & $\begin{array}{l}\text { Laporan perkembangan } \\
\text { proyek (berita acara). }\end{array}$ & $\begin{array}{l}\text { Laporan progres } \\
\text { proyek, dan laporan } \\
\text { absensi karyawan }\end{array}$ & $\begin{array}{l}\text { Untuk bahan } \\
\text { presentasi tentang } \\
\text { proyek. }\end{array}$ \\
\hline $\begin{array}{l}\text { Manjaer } \\
\text { keuangan }\end{array}$ & $\begin{array}{l}\text { Laporan anggaran } \\
\text { proyek. }\end{array}$ & $\begin{array}{l}\text { Laporan keuangan } \\
\text { proyek }\end{array}$ & \\
\hline
\end{tabular}




\begin{tabular}{|c|c|c|c|}
\hline Direksi & Ms. Word & Ms. Excel & Ms. Power Point \\
\hline Site manajer & $\begin{array}{l}\text { Laporan perencanaan } \\
\text { proyek, laporan kinerja } \\
\text { personil dan } \\
\text { timeschedule. }\end{array}$ & & \\
\hline Logistik & $\begin{array}{l}\text { Pengajuan material dan } \\
\text { alat, laporan persediaan } \\
\text { gudang dan daftar } \\
\text { supplier }\end{array}$ & & \\
\hline
\end{tabular}

Berdasarkan Tabel 1. Software yang digunakan setiap divisi perusahaan, Direktur Utama menggunakan Microsoft Word dan Microsoft Excel untuk membuat laporan tahunan perusahaan untuk diserahkan kepada komisaris perusahaan. Direktur Operasional menggunakan Microsoft Word dan Microsoft Excel untuk membuat laporan kegiatan operasional anggaran dan sumber daya perusahaan, sedangkan Microsoft Power Point untuk mempresentasikan pengadaan kegiatan hingga kegiatan selesai. Direktur Teknik menggunakan Microsoft Word dan Microsoft Excel untuk membuat laporan perkembangan proyek dan laporan akhir proyek yang dikerjakan perusahaan, sedangkan Microsoft Power Point untuk mempresentasikan perihal tentang proyek. Direktur Keuangan menggunakan Microsoft Word dan Microsoft Excel untuk membuat laporan keuangan perusahaan untuk harian sampai tahunan, sendangkan Microsoft Power Point untuk mempresentasikan keuangan perusahaan. Manajer Operasional dan Manajer Proyek menggunakan Microsoft Word dan Microsoft Excel untuk membuat laporan perkembangan proyek, laporan alat kontraktor dan sarana prasarana proyek, sendangkan Microsoft Power Point untuk mempresentasikan tender proyek perusahaan. Manajer Keuangan menggunakan Microsoft Word dan Microsoft Excel untuk membuat laporan keuangan proyek. Site Manajer menggunakan Microsoft Word untuk membuat lamporan perencanaan proyek, laporan kinerja karyawan dan time schedule. Logistik menggunakan Microsoft Word untuk membuat pengajuan material dan alat, laporan persediaan gudang dan dafar supplier.

\subsubsection{Hardware}

PT. Dian Hardesa sudah memanfaatkan teknologi dalam proses bisnisnya. Hal ini terbukti bahwa pada PT. Dian Hardesa terdapat 2 unit PC, 20 unit Laptop Asus intel i3, 13 unit Printer, dan 1 mesin Fotocopy. Selain itu, PT. Dian Hardesa telah memiliki jaringan Wi-Fi yang bisa dimanfaatkan oleh seluruh karyawan.

\subsection{Analisis Lingkungan Bisnis Perusahaan}

Mengidentifikasi lingkungan bisnis PT. Dian Hardesa, baik lingkungan bisnis internal Perusahaan maupun lingkungan bisnis eksternal perusahaan. Metode yang digunakan untuk menganalisis lingkungan bisnis perusahaan menggunakan metode Ward and Peppard dengan tools SWOT Analysis, Value Chain Analysis, Five Force Model Porter Analysis dan Critical Success Factors Analysis.

\subsubsection{Analisis SWOT}

Pada Analisis SWOT terdapat matriks analisis strategi strength dengan opportunities, matriks analisis strategi weakness dengan opportunities, matriks analisis strategi strength dengan threats, dan matriks analisis strategi weakness dengan threats.

Tabel 1. Matriks strength and opportunities

$$
\text { Strategi } \mathrm{S}-\mathrm{O}
$$

1. Memiliki hubungan baik dengan mitra kerja, pengalaman perusahaan dan surat ijin usaha untuk mendapatkan tender proyek.

2. Memiliki SDM yang berkompeten dibidangnya serta mampu memanfaatkan teknologi informasi untuk meningkatkan daya saing perusahaan.

3. Lokasi perusahaan ada di Jakarta, dekat dengan kota besar seperti Bogor, Depok, Bekasi dan Tangerang.

4. Memanfaatkan hubungan baik dengan supplier untuk mendapatkan pelanggan tetap.

5. Menjaga hubungan baik dengan bank, untuk mendapatkan pinjaman uang apabila terjadi krisis ekonomi salah satunya Bank Mandiri.

6. Menggunakan alat yang berkualitas dan kemampuan perencnaan pengerjaan proyek bagian operasional yang tepat untuk mendapatkan pelanggan tetap. 
Berdasarkan Tabel 1. Matriks strength and opportunities, strategi ini dilakukan untuk memanfaatkan kekuatan perusahaan sebagai peluang seperti hubungan baik dengan supplier dan mitra kerja, mendapatkan kepercayaan dari pihak bank untuk melakukan peminjaman dan memiliki SDM yang mampu memanfaakan teknologi informasi untuk meningkatkan daya saing perusahaan.

Tabel 2. Matriks weakness and opportunities

\section{Strategi $W-O$}

1. Harga material yang melonjak, untuk mengatasi permasalahan tersebut PT. Dian Hardesa memiliki kerjasama dengan beberapa supplier.

2. Menggunakan peluang kemajuan teknologi informasi, teknologi komunikasi dan sistem informasi untuk memaksimalkan pemanfaatan teknologi informasi dalam proses bisnis dan promosi.

3. Memanfaatkan hubungan baik dengan supplier tetap untuk memudahkan dalam mendapatkan informasi update harga material dan alat kontraktor.

4. Membuat laporan keuangan secara rutin untuk mendapatkan pelanggan tetap karena semua pihak menyukai laporan yang tepat waktu.

5. Memanfaatkan kemajuan SI/TI untuk mempermudah proses monitoring persediaan gudang.

Berdasarkan Tabel 2. Matriks weakness and opportunities, strategi digunakan pada saat peluang perusahaan mampu mengatasi ancaman proses bisnis perusahaan seperti memiliki banyak kerjasama terhadap supplier guna mendapatkan informasi update harga sekaligus mencari harga beli rendah dan perusahaan menjualnya dengan harga tinggi, pembuatan laporan keuangan yang tepat waktu dengan memanfaatkan teknologi informasi.

Tabel 3. Matriks strenght and threats Strategi $S-T$

1. Menggunakan kerjasama dan hubungan baik yang dimiliki dengan Mitra kerja dan Supplier untuk mengatasi ancaman naiknya harga material dan alat bangunan serta naiknya nilai dolar.

2. Menggunakan hubungan baik dengan pelanggan untuk mengatasi ancaman terlambatnya pengiriman barang.

3. Mempekerjakan karyawan berdasarkan kemapuan dan pengalaman yang dimiliki, sehingga memiliki SDM yang kompeten dibidangnya (berkualitas) dan menggunakan kemampuan operasional untuk mengatasi tingginya persaingan kontraktor jasa konstruksi.

4. Memanfaatkan kemampuan diskusi yang baik dan komunikasi yang baik untuk mengatasi kondisi lingkungan yang tidak kondusif.

5. Memperkejakan tenaga profesional untuk mendapatkan tender proyek.

Berdasarkan Tabel 3. Matriks strenght and threats, strategi digunakan sebagai kekuatan perusahaan untuk mengatasi ancaman yang dihadapi seperti memiliki hubungan baik dengan supplier dan mitra kerja dalam bekerjasama proses bisnis, untuk mengatasai meminimalisir keterlambatan pengiriman barang, memperkerjakan para karyawan berkompeten sehingga mendapatkan kepercayaan dari pelanggan.

Tabel 4. Matriks weakness and threats

\begin{tabular}{l} 
Strategi $\boldsymbol{W}-\boldsymbol{T}$ \\
\hline $\begin{array}{l}\text { 1. Melakukan promosi yang gencar sehingga tidak kalah saing dengan perusahaan } \\
\text { sejenis lain. }\end{array}$ \\
2. Memaksimalkan peran sistem informasi dan teknologi informasi pada \\
perusahaan sehingga tidak kalah saing dengan perusahaan sejenis.
\end{tabular}

Berdasarkan Tabel 4. Matriks weakness and threats, digunakan untuk mengatasi kelemahan perusahaan agar terhindar dari ancaman seperti melakukan promosi dan memaksimalkan peran teknologi informasi sebagai keunggulan meningkatkan daya saing perusahaan. 


\subsubsection{Analisis Critical Succes Factors}

Menganalisis faktor-faktor yang menjadi penentu keberhasilan PT. Dian Hardesa dalam mencapai tujuan perusahaan. Berdasarkan hasilwawancara dan observasi, maka didapatkan tujuan dan identifikasi Critical Success Factor seperti pada Tabel 5. Critical succes factors:

Tabel 5. Critical succes factors

\begin{tabular}{|c|c|c|c|}
\hline Tujuan Organisasi & Action & Tujuan Strategi & Measure \\
\hline Direktur Utama & $\begin{array}{l}\text { Rekruitmen calon } \\
\text { karyawan. } \\
\text { Kesetiaan Mitra } \\
\text { Kerja. }\end{array}$ & $\begin{array}{l}\text { Karyawan yang } \\
\text { berkompeten } \\
\text { Menjaga hubungan baik } \\
\text { dengan Mitra Kerja. }\end{array}$ & $\begin{array}{l}\text { Memiliki kompeten } \\
\text { dibidangnya. } \\
\text { Mitra Kerja ingin } \\
\text { bekerjasama dengan } \\
\text { PT. Dian Hardesa }\end{array}$ \\
\hline Direktur Keuangan & $\begin{array}{l}\text { Keuangan } \\
\text { perusahaan dikelola } \\
\text { dengan baik. }\end{array}$ & $\begin{array}{l}\text { Menjaga kepercayaan } \\
\text { pelanggan. }\end{array}$ & $\begin{array}{l}\text { Pelanggan puas } \\
\text { dengan laporan } \\
\text { keuangan. }\end{array}$ \\
\hline \multirow[t]{2}{*}{ Direktur Operasional } & $\begin{array}{l}\text { Pemilihan tender } \\
\text { yang tepat serta } \\
\text { informasi } \\
\text { perusahaan yang } \\
\text { tersebar luas dan } \\
\text { mudah dicari }\end{array}$ & $\begin{array}{l}\text { Mendapatkan tender } \\
\text { yang tepat agar } \\
\text { meningkatkan nilai } \\
\text { profit. }\end{array}$ & Profit meningkat \\
\hline & dan prasarana & $\begin{array}{l}\text { Mempermudah } \\
\text { karyawan dalam } \\
\text { mengerjakan proses } \\
\text { bisnis. }\end{array}$ & $\begin{array}{l}\text { Memiliki sarana dan } \\
\text { prasarana yang } \\
\text { memadai untuk } \\
\text { karyawan. }\end{array}$ \\
\hline Direktur Teknik & $\begin{array}{l}\text { Pengawasan } \\
\text { lapangan proyek. }\end{array}$ & $\begin{array}{l}\text { Meningkatkan } \\
\text { kepercayaang kepada } \\
\text { pemilik tender. }\end{array}$ & $\begin{array}{l}\text { Semakin banyaknya } \\
\text { proyek yang } \\
\text { diperoleh dan pemilik } \\
\text { tender percaya. }\end{array}$ \\
\hline Manajer Operasional & $\begin{array}{l}\text { Perencanaan atau } \\
\text { metode pengerjaan } \\
\text { proyek }\end{array}$ & $\begin{array}{l}\text { Untuk mendapatkan } \\
\text { pelanggan tetap. }\end{array}$ & $\begin{array}{l}\text { Pelanggan yang ingin } \\
\text { selalu bekerjasama } \\
\text { dengan PT. Dian } \\
\text { Hardesa dan tidak } \\
\text { mau berpaling dari } \\
\text { PT. Dian Hardesa. }\end{array}$ \\
\hline Manajer Proyek & $\begin{array}{l}\text { Pengawasan } \\
\text { gudang. }\end{array}$ & $\begin{array}{l}\text { Memonitoring } \\
\text { persediaan gudang agar } \\
\text { tidak mengalami } \\
\text { kelebihan atau } \\
\text { kekurangan material. }\end{array}$ & $\begin{array}{l}\text { Tidak pernah } \\
\text { kekurangan atau } \\
\text { bahkan kelebihan } \\
\text { material. }\end{array}$ \\
\hline \multicolumn{2}{|c|}{$\begin{array}{l}\text { Hubungan baik dengan } \\
\text { supplier dan pelanggan. }\end{array}$} & $\begin{array}{l}\text { Mempermudah proses } \\
\text { negoisasi saat harga } \\
\text { material naik secara } \\
\text { tiba-taba dan } \\
\text { menghindari kerugian } \\
\text { perusahaan. }\end{array}$ & $\begin{array}{l}\text { Memiliki supplier } \\
\text { tetap }\end{array}$ \\
\hline Manajer Keuangan & $\begin{array}{l}\text { Keuangan } \\
\text { perusahaan yang } \\
\text { dikelola dengan } \\
\text { baik. }\end{array}$ & $\begin{array}{l}\text { Menjaga kepercayaan } \\
\text { pelanggan dengan } \\
\text { membuat laporan yang } \\
\text { tepat waktu. }\end{array}$ & $\begin{array}{l}\text { Keuangan proyek } \\
\text { terkelola dengan } \\
\text { baik. }\end{array}$ \\
\hline
\end{tabular}

Berdasarkan Tabel 5. Critical Succes Factors, secara umum proses rekruitmen calon karyawan harus memiliki bidang keahlian khusus dan dibutuhkan oleh perusahaan yang nantinya dapat saling bersinergi disetiap divisi perusahaan. Harga relatif lebih murah dalam hal ini perusahaan memiliki kerja sama dengan supplier yang banyak sehingga mampu menekan biaya operasional dengan harga beli yang murah dan mendapatkan harga jual yang tinggi, Mendapatkan pelanggan tetap dari hasil pengerjaan yang maksimal dan mendapatkan kepercayaan pelanggan. 


\subsubsection{Value Chain Analysis}

Value Chain Analysis digunakan untuk mengidentifikasi dan pengelompokan aktivitas proses kerja yang terjadi pada PT. Dian Hardesa yang terdiri dari aktivitas utama dengan inbound logistic mengidentifikasi informasi tender, mendapatkan kontrak kerjsama, pengadaan calon karyawan, persediaan material dan alat kontraktor. Operation mengidentifikasi mengikuti tender, pelaksanaan proyek, monitoring persediaan gudang dan laporan keuangan secara rutin. Outbound logistic mengidentifikasi logistik memenangkan tender, penyerahan proyek dan laporan keuangan proyek. Services mengidentifikasi berkomunikasi yang baik dengan pelanggan, mitra kerja, supplier dan memberikan garansi material kepada pelanggan.

Untuk aktivitas pendukung seperti Firm Infrastruktur melakukan pengelompokan perencanaan keuangan, manajemen dan pengawasan proyek. Human resourecs management melakukan pengelompokan perekrutan, pelatihan dan penggajian karyawan. Technology development yang mengidentifikasi memaksimalkan pemanfaatan dan pengembangan sarana prasarana teknologi informasi. Procecurement mengidentifikasi pengajuan serta pembelian material alat kontraktor, kerjasama dengan supplier dan pembuatan gudang.

\subsubsection{Five Force Model Porter Analysis}

Tabel 6. Analisis five force model porter

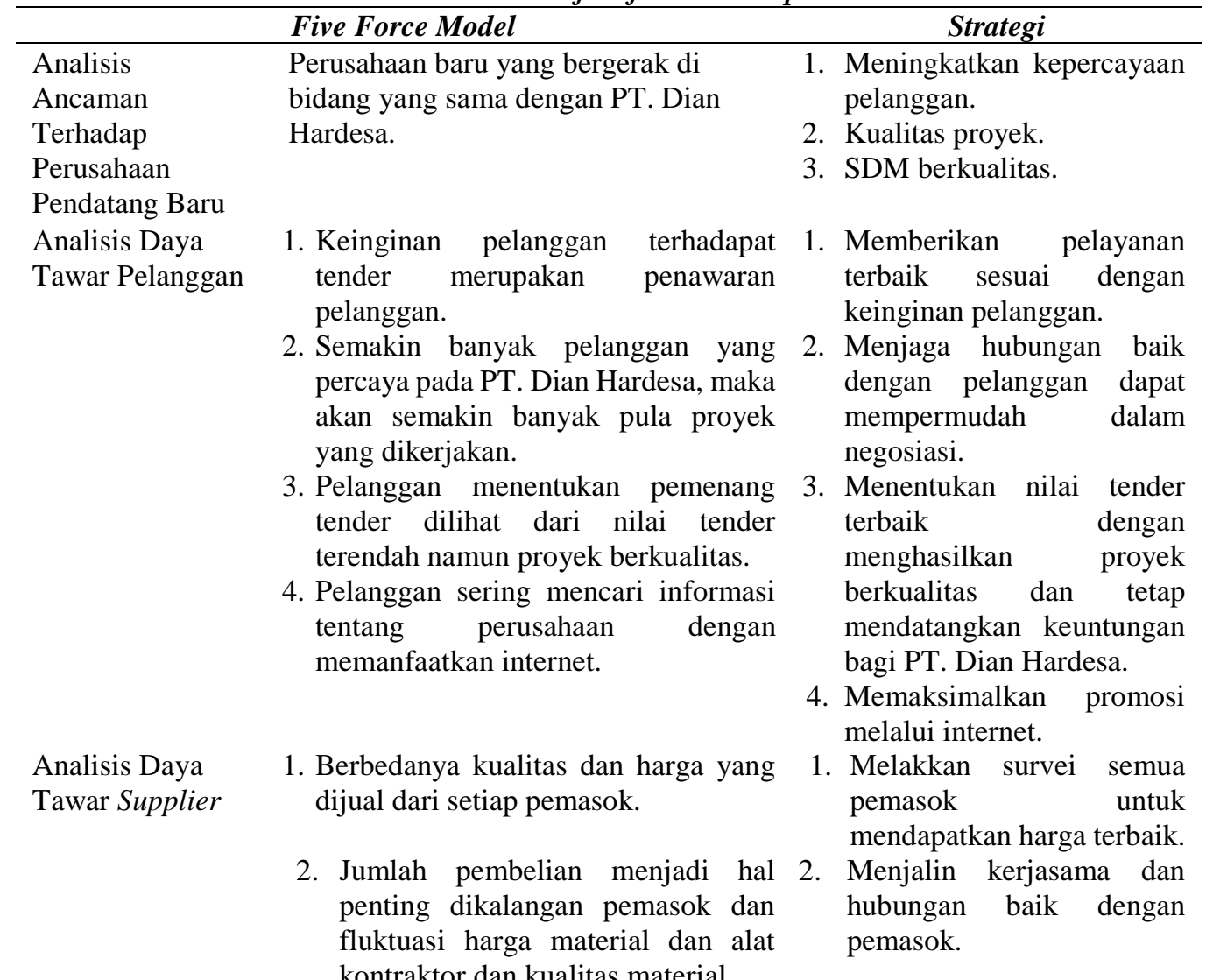

Analisis Produk Kontraktor Mekanikal, elektrikal dan Pengganti elektronik seperti tidak ada produk pengganti, karena pekerjaan jasa konstruksi memang biasanya dilakukan oleh kontraktor khususnya untuk proyek-proyek yang besar. Sedangkan untuk proyek yang kecil seperti perumahan, bisa digantikan oleh individual (tukang). Jadi, ancaman pengembangan produk pengganti adalah rendah.

Ancaman pengembangan produk pengganti termasuk rendah, PT. Dian Hardesa selalu memberikan pelayanaan yang baik, menjaga kepercayaan serta hubungan baik dengan pelanggan dan mitra kerja, selalu menjaga kualitas proyek dan kualitas waktu dalam pengerjaan proyek. 


\begin{tabular}{lll}
\hline & \multicolumn{1}{c}{ Five Force Model } & \multicolumn{1}{c}{ Strategi } \\
\hline Analisis & Persaingan perusahaan kontraktor & Memberikan pelayanaan yang \\
Intensitas & semakin meningkat setiap tahunnya. & baik dan hasil proyek \\
Persaingan & Data terakhir jumlah kontraktor & berkualitas, seperti tepat \\
& nasional di Indonesia yang mencapai & waktu pengerjaan proyek, \\
& 182.800 dan meningkat 5\% setiap & menjaga kualitas bahan baku, \\
& tahunnya. & mempersiapkan alat-alat \\
& & proyek dan pemanfaatan \\
& IT/IS. \\
\hline
\end{tabular}

Berdasarkan Tabel 6. Analisis Five Force Model Porter, ancaman terhadap perusahaan baru dengan caya meningkatkan kepercayaan pelanggan, hasil kualitas yang baik yang ditunjang dengan karyawan berkompeten dalam bidangnya. Daya tawar pelanggan dengan cara memberikan pelayanan terbaik, menjaga hubungan baik dengan pelanggan, harga yang rendah tapi memiliki kualitas terbaik dan memaksimalkan penggunaan teknologi informasi sebagai ajang promosi. Daya tawar supplier dengan cara melakukan survei seluruh pemasok material agar mendapatkan harga rendah memiliki kualitas produk terbaik. Produk pengganti untuk pekerjaan kontraktor mekanikal, elektrikan dan elektronik masih terbilang rendah karena proyek yang dikerjakan kategori besar, sedangkan kategori kecil dikerjakan indivdual atau bisa disebut dengan tukang.

\subsubsection{Strategi Bisnis dengan Kebutuhan Informasi}

Tabel 7. Pemetaan strategi dengan kebutuhan informasi

\begin{tabular}{|c|c|c|c|c|}
\hline $\begin{array}{c}\text { Tujuan } \\
\text { Organisasi }\end{array}$ & Action & SWOT & Value Chain & Kebutuhan Informasi \\
\hline \multirow{3}{*}{$\begin{array}{l}\text { Direktur } \\
\text { Utama }\end{array}$} & Rekruitmen & Mempekerjakan & Pengadaan atau & Biodata, EKTP, \\
\hline & $\begin{array}{l}\text { karyawan } \\
\text { yang } \\
\text { berkualitas }\end{array}$ & $\begin{array}{l}\text { karyawan yang } \\
\text { berkompeten. }\end{array}$ & $\begin{array}{l}\text { rekruitmen calon } \\
\text { karyawan. }\end{array}$ & $\begin{array}{l}\text { Pengalaman kerja dan } \\
\text { pendidikan. }\end{array}$ \\
\hline & $\begin{array}{l}\text { Kesetiaan } \\
\text { Mitra Kerja. }\end{array}$ & $\begin{array}{l}\text { Hubungan baik dengan } \\
\text { mitra kerja, citra } \\
\text { perusahaan yang baik, } \\
\text { pengalaman } \\
\text { perusahaan dan surat ijin } \\
\text { usaha tender proyek. }\end{array}$ & $\begin{array}{l}\text { Menjaga } \\
\text { hubungan baik } \\
\text { dengan Mitra } \\
\text { Kerja. }\end{array}$ & Biodata Mitra Kerja. \\
\hline $\begin{array}{l}\text { Direktur } \\
\text { Keuangan }\end{array}$ & $\begin{array}{l}\text { Keuangan } \\
\text { perusahaan } \\
\text { yang } \\
\text { dikelola } \\
\text { dengan baik. }\end{array}$ & $\begin{array}{l}\text { Laporan keuangan } \\
\text { secara rutin untuk } \\
\text { mendapatkan pelanggan } \\
\text { tetap karena semua } \\
\text { pihak menyukai laporan } \\
\text { yang tepat waktu. }\end{array}$ & $\begin{array}{l}\text { Membuat laporan } \\
\text { keuangan rutin. }\end{array}$ & $\begin{array}{l}\text { Penggajian, } \\
\text { JAMSOSTEK, } \\
\text { Tunjangan, Pajak/PPH, } \\
\text { Zakat, Kuitansi, berita } \\
\text { acara, buku besar, Buku } \\
\text { BANK. }\end{array}$ \\
\hline \multirow[t]{5}{*}{$\begin{array}{l}\text { Direktur } \\
\text { operasional }\end{array}$} & $\begin{array}{l}\text { Pemilihan } \\
\text { tender yang } \\
\text { tepat }\end{array}$ & $\begin{array}{l}\text { Karyawan berkompeten } \\
\text { sehingga mengatasi } \\
\text { tingginya persaingan } \\
\text { kontraktor jasa } \\
\text { konstruksi. }\end{array}$ & $\begin{array}{l}\text { Rekruitmen } \\
\text { karyawan. }\end{array}$ & $\begin{array}{l}\text { Nilai kontrak, jarak } \\
\text { proyek, lokasi proyek, } \\
\text { perkiraan biaya proyek, } \\
\text { sumber uang dan nilai } \\
\text { profit. }\end{array}$ \\
\hline & $\begin{array}{l}\text { Sarana dan } \\
\text { prasarana }\end{array}$ & $\begin{array}{l}\text { Fasilitas teknologi untuk } \\
\text { meningkatkan sistem } \\
\text { informasi dan teknologi. }\end{array}$ & $\begin{array}{l}\text { Pengadaan sarana } \\
\text { dan prasarana } \\
\text { perusahaan. }\end{array}$ & $\begin{array}{l}\text { Data sarana prasarana, } \\
\text { jumlah, spesifikasi, } \\
\text { harga, kualitas dan } \\
\text { kegunaan. }\end{array}$ \\
\hline & Gaji & Memanfaatkan & Laporan gaji & Penggajian, \\
\hline & $\begin{array}{l}\text { karyawan } \\
\text { tepat waktu }\end{array}$ & $\begin{array}{l}\text { kemajuan SI/TI untuk } \\
\text { mempermudah proses } \\
\text { monitoring persediaan } \\
\text { gudang. }\end{array}$ & karyawan & $\begin{array}{l}\text { JAMSOSTEK, } \\
\text { Tunjangan, Absensi, } \\
\text { Pajak/PPH, Zakat. }\end{array}$ \\
\hline & $\begin{array}{l}\text { Sarana dan } \\
\text { prasarana }\end{array}$ & $\begin{array}{l}\text { Fasilitas teknologi untuk } \\
\text { meningkatkan sistem } \\
\text { informasi dan teknologi. }\end{array}$ & $\begin{array}{l}\text { Pengadaan sarana } \\
\text { dan prasarana } \\
\text { perusahaan. }\end{array}$ & $\begin{array}{l}\text { Data sarana prasarana, } \\
\text { jumlah, spesifikasi, } \\
\text { harga, kualitas dan } \\
\text { kegunaan. }\end{array}$ \\
\hline
\end{tabular}




\begin{tabular}{|c|c|c|c|c|}
\hline $\begin{array}{c}\text { Tujuan } \\
\text { Organisasi }\end{array}$ & Action & SWOT & Value Chain & Kebutuhan Informasi \\
\hline $\begin{array}{l}\text { Direktur } \\
\text { Teknik }\end{array}$ & $\begin{array}{l}\text { Pengawasan } \\
\text { lapangan } \\
\text { proyek. }\end{array}$ & $\begin{array}{l}\text { Menggunakan teknisi } \\
\text { yang kompeten untuk } \\
\text { mendapatkan tender. }\end{array}$ & $\begin{array}{l}\text { Mengawasi } \\
\text { perkembangan } \\
\text { dan serah terima } \\
\text { proyek }\end{array}$ & $\begin{array}{l}\text { Progress proyek, } \\
\text { kendala dan solusinya. }\end{array}$ \\
\hline $\begin{array}{l}\text { Manajer } \\
\text { Operasiona } \\
1\end{array}$ & $\begin{array}{l}\text { Perencanaan } \\
\text { atau metode } \\
\text { pengerjaan } \\
\text { proyek }\end{array}$ & $\begin{array}{l}\text { Menggunakan alat yang } \\
\text { berkualitas dan } \\
\text { perencanaan proyek } \\
\text { untuk mendapatkan } \\
\text { pelanggan tetap. }\end{array}$ & $\begin{array}{l}\text { Laporan } \\
\text { perencanaan atau } \\
\text { metode } \\
\text { pengerjaan } \\
\text { proyek. }\end{array}$ & $\begin{array}{l}\text { Gambaran proyek, } \\
\text { ruang lingkup, dana } \\
\text { proyek, keinginan } \\
\text { pelanggan data tender. }\end{array}$ \\
\hline \multirow[t]{3}{*}{$\begin{array}{l}\text { Manajer } \\
\text { Proyek }\end{array}$} & $\begin{array}{l}\text { Pengawasan } \\
\text { gudang. }\end{array}$ & $\begin{array}{l}\text { Memanfaatkan teknologi } \\
\text { informasi. }\end{array}$ & $\begin{array}{l}\text { Memonitoring } \\
\text { persediaan } \\
\text { gudang. }\end{array}$ & $\begin{array}{l}\text { Data material, jumlah, } \\
\text { kegunaan dan harga }\end{array}$ \\
\hline & $\begin{array}{l}\text { Hubungan } \\
\text { baik dengan } \\
\text { supplier dan } \\
\text { pelanggan. }\end{array}$ & $\begin{array}{l}\text { Kerjasama dan } \\
\text { hubungan baik yang } \\
\text { dimiliki dengan Mitra } \\
\text { kerja dan Supplier untuk } \\
\text { mengatasi ancaman } \\
\text { naiknya harga material } \\
\text { dan alat bangunan serta } \\
\text { naiknya nilai dolar. }\end{array}$ & $\begin{array}{l}\text { Menjaga huungan } \\
\text { baik dengan } \\
\text { supplier. }\end{array}$ & $\begin{array}{l}\text { Data Supllier, nama, } \\
\text { nomor telephone, } \\
\text { alamat toko dan alamat } \\
\text { rumah. }\end{array}$ \\
\hline & $\begin{array}{l}\text { Gaji } \\
\text { karyawan } \\
\text { tepat waktu }\end{array}$ & $\begin{array}{l}\text { Memanfaatkan } \\
\text { kemajuan SI/TI untuk } \\
\text { mempermudah proses } \\
\text { monitoring } \\
\text { persediaan gudang. }\end{array}$ & $\begin{array}{l}\text { Laporan gaji } \\
\text { karyawan }\end{array}$ & $\begin{array}{l}\text { Absensi, gaji pokok dan } \\
\text { gaji lembur. }\end{array}$ \\
\hline $\begin{array}{l}\text { Manajer } \\
\text { Keuangan }\end{array}$ & $\begin{array}{l}\text { Keuangan } \\
\text { perusahaan } \\
\text { yang } \\
\text { dikelola } \\
\text { dengan baik. }\end{array}$ & $\begin{array}{l}\text { Membuat laporan } \\
\text { keuangan secara rutin } \\
\text { untuk mendapatkan } \\
\text { pelanggan tetap karena } \\
\text { semua pihak menyukai } \\
\text { laporan yang tepat } \\
\text { waktu. }\end{array}$ & $\begin{array}{l}\text { Mengelola } \\
\text { keuangan } \\
\text { perusahaan } \\
\text { (memonitoring } \\
\text { dan mengontrol) } \\
\text { keuangan proyek. }\end{array}$ & $\begin{array}{l}\text { Absensi, gaji pokok, } \\
\text { gaji lembur, kuitansi, } \\
\text { progres, berita acara } \\
\text { dan anggaran dana. }\end{array}$ \\
\hline
\end{tabular}

Berdasarkan Tabel 7. Pemetaan strategi dengan kebutuhan informasi, ditektur utama membutuhkan informasi berupa biodata untuk mengetahui kualitas dari calon karyawan yang berkualitas dan berkompeten, sedangkan informasi untuk menjaga hubungan baik dengan mitra kerja. Kebutuhan informasi untuk mengelola keuangan perusahaan yang dilakukan direktur keuangan adalah penggajian, jamsostek, tunjangan, pph, zakat, kuitansi, berita acara, buku besar dan buku bank. Kebutuhan informasi untuk pemilihan tender dan sarana prasarana yang dilakukan direktur operasional adalah nilai proyek, jarak proyek, lokasi proyek, biaya proyek, data sarana dan prasarana. Kebutuhan informasi untuk pengawasan pengerjaan proyek yang dilakukan direktur teknik adalah progres proyek dalam waktu tertentu, kendala pengerjaan proyek beserta solusi yang ditawarkan. Kebutuhan informasi perencanaan atau metode pengerjaan proyek yang dilakukan manajer operasional adalah gambaran proyek, ruang lingkup, dana proyek dan keinginan pelanggan data tender. Kebutuhan informasi untuk data material, jumlah material, kegunaan material, harga material dan identitas data supplier berupa nama, nomor telephone, alamat toko, dll. Kebutuhan informasi untuk membuat laporan keuangan perusahaan yang dilakukan manajer keuangan adalah absensi, gaji pokok, gaji lembur, kuitansi, progres pengerjaan proyek, progres kinerja karyawan, berita acara dan anggaran dana.

\subsection{Analisis Strategi Sistem Informasi}

\subsubsection{Strategi Sistem Informasi}

Strategi sistem informasi merupakan tahap menentukan penyusunan dan strategi yang akan datang berdasarkan hasil analisis sebelumnya dan digunakan sebagai acuan untuk pembuatan perencanaan strategis sistem informasi. Strategi bisnis sistem informasi pada tahap ini adalah bertujuan untuk mengidentifikasi strategi bisnis serta menentukan solusi sistem informasi yang sesuai dengan kebutuhan PT. Dian Hardesa. 
Solusi sistem informasi diidentifikasin berdasarkan hasil analisis SWOT, Value Chain, Critical Success Factor.

Strategi ini dibuat sesuai dengan kebutuhan dari masing-masing Direksi yang ada di PT. Dian Hardesa guna meningkatkan daya saing perusahaan. Pemetaan strategi yang dibuat mengacu pada tool Critical Success Factor atau faktor-faktor penentu keberhasil perusahaan dalam mencapai tujuan perusahaannya.

\subsubsection{Analisis Kebutuhan Sistem}

Untuk menganalisis strategi yang sesuai dengan kebutuhan perusahaan guna meningkatkan daya saing perusahaan, maka diperlukan analisis kebutuhan sistem. Analisis kebutuhan sistem yang setiap direksi yang ada di PT. Dian Hardesa, dapat dilihat seperti Tabel 8. Analisis kebutuhan sistem critical susccess factor:

Tabel 8. Analisis kebutuhan sistem dengan critical success factor

\begin{tabular}{|c|c|c|c|}
\hline $\begin{array}{c}\text { Tujuan } \\
\text { Organisasi }\end{array}$ & Kebutuhan Sistem & Tujuan Strategi & $\begin{array}{l}\text { Critical Success } \\
\text { Factor (Action) }\end{array}$ \\
\hline $\begin{array}{l}\text { Direktur } \\
\text { Utama }\end{array}$ & $\begin{array}{l}\text { Proses rekruitmen karyawan dan } \\
\text { meningkatkan SDM. } \\
\text { Menjada hubungan baik dengan } \\
\text { Mitra Kerja. }\end{array}$ & $\begin{array}{l}\text { Melahirkan SDM kompeten } \\
\text { dibidangnya. } \\
\text { Menjaga hubungan baik } \\
\text { dengan Mira Kerja. }\end{array}$ & $\begin{array}{l}\text { Karyawan yang } \\
\text { berkualitas } \\
\text { Kesetiaan Mitra } \\
\text { Kerja. }\end{array}$ \\
\hline $\begin{array}{l}\text { Direktur } \\
\text { Keuangan }\end{array}$ & $\begin{array}{l}\text { Digunakan untuk mengelola } \\
\text { keuangan perusahaan. }\end{array}$ & $\begin{array}{l}\text { Menjaga kepercayaan } \\
\text { pelanggan dengan membuat } \\
\text { laporan yang tepat waktu. }\end{array}$ & $\begin{array}{l}\text { Keuangan } \\
\text { perusahaan yang } \\
\text { dikelola dengan } \\
\text { baik. }\end{array}$ \\
\hline \multirow[t]{2}{*}{$\begin{array}{l}\text { Direktur } \\
\text { Operasional }\end{array}$} & $\begin{array}{l}\text { Digunakan untuk memilih } \\
\text { tender dan memberikan } \\
\text { informasi perusahaan pada } \\
\text { pemilik tender. }\end{array}$ & $\begin{array}{l}\text { Mendapatkan tender agar } \\
\text { meningkatkan nilai profit. }\end{array}$ & $\begin{array}{l}\text { Informasi tender } \\
\text { yang tersebar luas } \\
\text { dan mudah dicari. }\end{array}$ \\
\hline & $\begin{array}{l}\text { Digunakan untuk mengelola } \\
\text { sarana dan prasarana. }\end{array}$ & $\begin{array}{l}\text { Mempermudah karyawan } \\
\text { mengerjakan proses bisnis. }\end{array}$ & $\begin{array}{l}\text { Sarana dan } \\
\text { prasarana. }\end{array}$ \\
\hline Direktur & Digunakan untuk monitoring & Meningkatkan kepercayaan & Pengawasan \\
\hline Teknik & perkembangan proyek. & kepada pemilik tender. & lapangan proyek. \\
\hline $\begin{array}{l}\text { Manajer } \\
\text { Operasional }\end{array}$ & $\begin{array}{l}\text { Digunakan untuk mengolah, } \\
\text { menyimpam dan perencanaan } \\
\text { proyek. }\end{array}$ & $\begin{array}{l}\text { Untuk mendapatkan } \\
\text { pelanggan tetap. }\end{array}$ & $\begin{array}{l}\text { Perencanaan atau } \\
\text { metode pengerjaan } \\
\text { proyek. }\end{array}$ \\
\hline $\begin{array}{l}\text { Manajer } \\
\text { Proyek }\end{array}$ & $\begin{array}{l}\text { Digunakan untuk memonitoring } \\
\text { persediaan gudang. }\end{array}$ & $\begin{array}{l}\text { Tidak mengalami kelebihan } \\
\text { atau kekurangan. }\end{array}$ & $\begin{array}{l}\text { Pengawasan } \\
\text { gudang. }\end{array}$ \\
\hline & $\begin{array}{l}\text { Digunakan menjaga hubungan } \\
\text { baik dengan pelanggan dan } \\
\text { supplier. }\end{array}$ & $\begin{array}{l}\text { Mempermudah proses } \\
\text { negoisasi saat harga naik } \\
\text { secara tiba-taba dan } \\
\text { menghindari kerugian. }\end{array}$ & $\begin{array}{l}\text { Hubungan baik } \\
\text { dengan supplier. }\end{array}$ \\
\hline $\begin{array}{l}\text { Manajer } \\
\text { Keuangan }\end{array}$ & $\begin{array}{l}\text { Digunakan untuk mengelola } \\
\text { keuangan proyek. }\end{array}$ & $\begin{array}{l}\text { Menjaga kepercayaan } \\
\text { pelanggan dengan membuat } \\
\text { laporan yang tepat waktu. }\end{array}$ & $\begin{array}{l}\text { Keuangan } \\
\text { perusahaan yang } \\
\text { dikelola dengan } \\
\text { baik. }\end{array}$ \\
\hline
\end{tabular}

\subsubsection{Arsitektur Aplikasi}

Arsitektur aplikasi meruapakan strategis sistem informasi yang sesuai dengan apa yang dibutuhkan PT. Dian Hardesa. Arsitektur yang dibuat mengacu pada tool Critical Success Factor seperti pada Tabel 9 Arsitektur Aplikasi Menggunakan Critical Success Factor: 
Tabel 9. Arsitektur aplikasi dengan critical success factor

\begin{tabular}{|c|c|c|c|}
\hline $\begin{array}{c}\text { Tujuan } \\
\text { Organisasi }\end{array}$ & Kebutuhan Sistem & Strategi SI & Action \\
\hline \multirow[t]{3}{*}{ Direktur Utama } & $\begin{array}{l}\text { Digunakan untuk membantu } \\
\text { dalam proses rekruitmen } \\
\text { karyawan dan meningkatkan } \\
\text { SDM. }\end{array}$ & $\begin{array}{l}\text { 1. SPK Rekruitmen } \\
\text { karyawan. }\end{array}$ & $\begin{array}{l}\text { Karyawan yang } \\
\text { berkualitas }\end{array}$ \\
\hline & & $\begin{array}{l}\text { 2. Knowledge } \\
\text { Management } \\
\text { System. }\end{array}$ & \\
\hline & $\begin{array}{l}\text { Digunakan untuk menjaga } \\
\text { hubungan baik dengan mitra } \\
\text { kerja. }\end{array}$ & SI Mitra Kerja & $\begin{array}{l}\text { Kesetiaan Mitra } \\
\text { Kerja }\end{array}$ \\
\hline Direktur & Digunakan untuk mengelola & 1.SI Keuangan & Keuangan perusahaan \\
\hline Keuangan & keuangan perusahaan. & $\begin{array}{l}\text { 2. SI Gaji Karyawan } \\
\text { 3. SI Absensi } \\
\text { 4. SI Karyawan }\end{array}$ & $\begin{array}{l}\text { yang dikelola dengan } \\
\text { baik. }\end{array}$ \\
\hline \multirow[t]{2}{*}{$\begin{array}{l}\text { Direktur } \\
\text { Operasional }\end{array}$} & $\begin{array}{l}\text { Digunakan untuk memilih tender } \\
\text { yang tepat dan memberikan } \\
\text { informasi perusahaan pada } \\
\text { pemilik tender. }\end{array}$ & $\begin{array}{lr}\text { 1. SPK } & \text { Pemilihan } \\
\text { Tender } & \\
\text { 2. Website, } & \text { Sosial } \\
\text { Media } & \end{array}$ & $\begin{array}{l}\text { Pemilihan tender } \\
\text { yang tepat serta } \\
\text { informasi perusahaan } \\
\text { yang tersebar luas } \\
\text { dan mudah dicari. }\end{array}$ \\
\hline & $\begin{array}{l}\text { Digunakan untuk mengelola } \\
\text { sarana dan prasarana. }\end{array}$ & SI Manajemen Aset & Sarana dan prasarana \\
\hline Direktur Teknik & $\begin{array}{l}\text { Digunakan untuk monitoring } \\
\text { perkembangan proyek. }\end{array}$ & $\begin{array}{l}\text { Contructor Planning } \\
\text { Application }\end{array}$ & $\begin{array}{l}\text { Pengawasan lapangan } \\
\text { proyek. }\end{array}$ \\
\hline $\begin{array}{l}\text { Manajer } \\
\text { Operasional }\end{array}$ & $\begin{array}{l}\text { Digunakan untuk mengolah, } \\
\text { menyimpam dan perencanaan } \\
\text { proyek. }\end{array}$ & $\begin{array}{l}\text { Contructor Planning } \\
\text { Application }\end{array}$ & $\begin{array}{l}\text { Perencanaan atau } \\
\text { metode pengerjaan } \\
\text { proyek }\end{array}$ \\
\hline \multirow[t]{2}{*}{ Manajer Proyek } & $\begin{array}{l}\text { Digunakan untuk memonitoring } \\
\text { persediaan gudang. }\end{array}$ & $\begin{array}{l}\text { SI Persediaan } \\
\text { Gudang }\end{array}$ & Pengawasan gudang. \\
\hline & $\begin{array}{l}\text { Sistem yang bisa menjaga } \\
\text { hubungan baik dengan pelanggan } \\
\text { dan supplier. }\end{array}$ & $\begin{array}{l}\text { SI Pelanggan dan } \\
\text { Supplier }\end{array}$ & $\begin{array}{l}\text { Hubungan baik } \\
\text { dengan supplier. }\end{array}$ \\
\hline $\begin{array}{l}\text { Manajer } \\
\text { Keuangan }\end{array}$ & $\begin{array}{l}\text { Sistem yang bisa digunakan untuk } \\
\text { mengelola keuangan proyek. }\end{array}$ & $\begin{array}{l}\text { 1. SI Keuangan } \\
\text { 2. SI Gaji Karyawan } \\
\text { 3. SI Absensi } \\
\text { 4. SI Karyawan }\end{array}$ & $\begin{array}{l}\text { Keuangan perusahaan } \\
\text { yang dikelola dengan } \\
\text { baik. }\end{array}$ \\
\hline
\end{tabular}

\subsection{Rancangan Portofolio Aplikasi Mendatang}

Dari hasil perumusan strategi sistem informasi dapat ditemukan beberapa sistem informasi yang sesuai dengan kebutuhan perusahaan, hampir dari keseluruhan merupakan sistem baru yang belum diimplementasi pada perusahaan. Selanjutnya solusi-solusi sistem informasi tersebut akan dipetakan dalam Portofolio MCFarlan Strategic Grid. Portofolio sistem informasi yang dihasilkan pada Tabel 10 Rekomendasi Portofolio Sistem Informasi MCFarlan Strategic Grid:

Tabel 10. Rekomendasi portofolio sistem informasi mc farlan strategic grid

\begin{tabular}{ll}
\hline Strategic & High potential \\
\hline SPK Pemilihan Tender & Website, Media Sosial \\
Knowledge Management System & SI Manajemen Aset \\
SI Rekruitmen Karyawan & SI Mitra Kerja \\
& SI Pelanggan \\
& SI Supplier \\
SI Keuangan & SI Absensi \\
SI Manajemen Karyawan & SI Penggajian \\
Contructor Planning Application & SI Persediaan Gudang \\
Key operational & Support \\
\hline
\end{tabular}


Berdasarkan pada Tabel 10. Rekomendasi portofolio sistem informasi mc farlan srategic grid, secara keseluruhan solusi sistem informasi baru yang belum pernah diimplementasikan di PT. Dian Hardesa dengan kategori sebagai berikut:

\subsubsection{High Potential}

Aplikasi yang mungkin penting dalam mencapai keunggilan kompetitif perusahaan. Usulan sistem informasi nya yaitu Website, Media Sosial, SI Manajemen Aset, SI Mitra Kerja, SI Pelanggan dan SI Supplier diharapkan dapat mendukung proses bisnis PT. Dian Hardesa dimasa sekarang dan dimasa yang akan datang.

\subsubsection{Key Operation}

Sistem informasi yang penting untuk mendukung kelangsungan bisnis perusahaan dan harus selalu dijaga efektifannya. Adapun usulan sistem informasi nya yaitu SI Keuangan, SI Manajemen Karyawan dan Contructor Planning Application. Sistem informasi ini merupakan sistem informasi yang setiap.

\subsubsection{Strategic}

Sistem informasi yang memiliki pengaruh besar untuk kesuksesan petusahaan, yang masuk kategori sistem informasi yaitu: SPK Pemilihan Tender, Knowledge Management System dan SI Rekruitmen Karyawan. Sistem informasi ini memiliki pengaruh besar untuk kesuksesan perusahaan dimasa datang. Dengan adanya Knowledge Management System dan SI Rekruitmen Karyawan PT. Dian Hardesaa bisa memiliki SDM yang berkualitas atau kompeten dibidangnya. Karena faktor utama kesuksesan dari perusahaan terletak pada SDM.

\subsubsection{Support}

Aplikasi yang bernilai tetapi tidak kritis dalam mencapai kesuksesan suatu perusahaan atau sistem informasi pendukung saja yang masuk kategori sistem informasi yaitu: SI Absensi, SI Penggajian dan SI Persediaan Gudang

\section{KESIMPULAN}

Penelitian perencanaan information system strategy pada PT. Dian Hardesa menghasilkan rekomendasi portofolio sistem informasi keuangan, sistem informasi karyawan, sistem informasi absensi, sistem informasi ketersediaan barang, sistem informasi pelanggan, sistem informasi supplier, sistem informasi mitra kerja, sistem informasi manajemen aset, website perusahaan, sosial media, knowledge management system, contructor planning application, sistem penunjang keputusan tender dan sistem penunjang keputusan rekruitmen karyawan.

\section{DAFTAR PUSTAKA}

[1] Afriyanto, Muhammad., et al. 2016. "Perencanaan Strategis Sistem Informasi Menggunakan Metode Ward and Peppard Pada PT. Grahacipta Bangko Jaya.” e-Proceeding of Engineering Vol 3. No 1, ISNN 2355-9365.

[2] Faslah, Ronny., dan Haris, Abdul. 2017. "Perencanaan Strategis Sistem Informasi." Jurnal ELTIKOM Vol 1. No 1, ISSN 2598-3245.

[3] Jogiyanto. (2006). Sistem Informasi Strategik Untuk Keunggulan Kompetitif. Yogyakarta: Andi Offset.

[4] Markas, M, George., dan O’Brien, A, James. (2017). Pengantar Sistem Informasi Introduction to Information Systems. Jakarta Selatan: Salemba Empat.

[5] Maryani dan Darudianto, Suparto. 2010. "Perancangan Rencana Strategis Sistem Informasi Dan Teknologi Informasi (SI/TI): Studi Kasus STMIK XYZ”. Jurnal Sistem Informasi Vol 4. No 2, ISSN 1969-0659.

[6] Saragih, Hoga., dan Harisno. (2014). Rencana Strategis Teknologi Informasi (IT) dan Sistem Informasi (IS) pada Proses Bisnis Perusahaan. Yogyakarta: Graha Ilmu.

[7] Setiawan, Satria Heri. 2016. "Perencanaan Strategis Sistem Informasi PT. FM Guna Meningkatkan Daya Saing Menggunakan Ward and Peppard". e-Proceeding of Engineering Vol 5. No 8, ISSN 2355-9365.

[8] Yandi, Zukkri,. et al. 2014. "Perencanaan Strategis Sistem Informasi Pada PT. Optima Trading. Studi Informasi.” Jurnal Sistem Informasi Vol 7. No 1,ISSN 1979-0767. 